\title{
Identification of reliable reference genes for quantitative real-time PCR normalization in pitaya
}

\author{
Canbin Chen ', Jingyu Wu' ', Qingzhu Hua', Noemi Tel-Zur², Fangfang Xie' , Zhike Zhang ${ }^{1}$, Jianye Chen', \\ Rong Zhang ${ }^{1}$, Guibing $\mathrm{Hu}^{1}$, Jietang Zhao ${ }^{1}$ and Yonghua Qin ${ }^{1 *}$
}

\begin{abstract}
Background: A suitable reference gene is an important prerequisite for guarantying accurate and reliable results in quantitative real-time PCR (qRT-PCR) analyses. However, there is no absolute universality in reference genes among different species. It's hard to find an ideal reference gene to fit for different tissues and growth periods. Pitaya (Hylocereus) is commercially produced as a new fruit crop at a large scale in tropical and subtropical regions. To date, there is no report on the identification of the most reliable reference genes for qRT-PCR normalization in pitaya.

Results: In this study, six candidate reference genes i.e. Actin(1), GAPDH, UBC(1), UBC(2) EF1- $a(1)$ and histone(1) were selected from thirty-nine typical candidate reference genes to determine the most stable reference genes for qRT-PCR normalization in different tissues, temperature stresses and fruit developmental stages of pitaya. Among the six candidate reference genes, Actin(1) and EF1-a(1) were the most stable gene according to calculations of three statistical methods (GeNorm, NormFinder and BestKeeper) while $U B C(1)$ and $U B C(2)$ showed the lowest expression stability. The six candidate reference genes were further validated by comparing expression profiles of key genes related to betalain biosynthesis at flesh coloration stages of Guanhuahong (Hylocereus monacanthus) and Guanhuabai (H. undatus) pitayas. Actin(1) was recommended the best reference gene for accurate normalization of qRT-PCR data.
\end{abstract}

Conclusions: In this study, the stability of the selected reference genes for normalizing the qRT-PCR data were identified from pitaya. Actin(1) was the most stably expressed genes in different tissues and fruit developmental stages in pitaya. The present work provides the first data of reference gene identification for pitaya and will facilitate further studies in molecular biology and gene function on Hylocereus and other closely related species.

Keywords: Hylocereus, Reference genes, Identification, qRT-PCR, Normalization, Cytochrome P450 gene

\section{Background}

Quantitative real-time PCR (qRT-PCR) is a nucleic acid quantitative technology to study gene expression level in molecular biology research [1]. It combines the sensitivity of conventional PCR with a cost-effective assay using a specific fluorescent signal. Compared with northern

\footnotetext{
*Correspondence: qinyh@scau.edu.cn

${ }^{1}$ State Key Laboratory for Conservation and Utilization of Subtropical Agro-bioresources/Guangdong Provincial Key Laboratory of Postharvest Science of Fruits and Vegetables/Key Laboratory of South China Horticultural Crop Biology and Germplasm Enhancement, Ministry of Agriculture, College of Horticulture, South China Agricultural University, Guangzhou 510642, China

Full list of author information is available at the end of the article
}

blot and conventional RT-PCR, qRT-PCR is proven to be highly sensitive and specific and has been increasingly used in various research fields of biological sciences [2-4]. A stable reference gene plays an important role in analyzing the relative expression levels of target genes [5]. Reference gene, i.e. internal reference gene, whose expression is relatively constant in various tissues and cells, can be used as the reference in the detection of gene relative expression analyses. However, transcription levels of reference gene may change in different species, treatments and/or developmental stages. Therefore, it is necessary to validate the expression stability of reference 
genes under various tissues and experimental conditions in different species.

The accuracy of gene expression levels using qRT-PCR depends on the use of stable reference genes to normalize the difference between samples [6]. GAPDH, Actin, $18 S$ rRNA, $28 S$ rRNA, tubulin, EF1- $\alpha$ and ubiquitin are commonly used as reference genes for comparison of samples [7-9]. Reference genes are always expressed because they produce proteins that cells must have to function, however, the stability of reference genes is limited in different tissues, growth and development stages of the same or different plants [10-15]. Therefore, it is necessary to select the most suitable reference gene for accurate qRTPCR evaluation according to different species and experimental conditions $[16,17]$. In addition, calculations of reference genes by geNorm [6], NormFinder [18] and BestKeeper [19] is essential for normalization of qRTPCR analyses.

Pitaya or pitahaya, also known as dragon fruit, originated from rainforest in tropical and subtropical areas of Central America and Mexico. Pitaya belongs to the genus Hylocereus in the Cactaceae family. Currently, redflesh and white-flesh pitayas have been commercially produced as a new fruit crop at a large scale in Central America, Southeast Asia and China. Pitaya is a fast growing, perennial, hemi-epiphytic, vine-like, crassulacean acid metabolism (CAM) plant. It is a spiny succulent plant which can adapt to a wide ecological range such environmental cues as drought, heat and poor soil. Pitaya has gained great attention of the world due to its high nutritional value as well as its antioxidant capacity and antiproliferative activities [20-22]. Therefore, the knowledge about the molecular basis of pitaya may contribute to the discovery of new and promising genes related to important agricultural traits that could be further transferred to a target crop for the development of new crop cultivars.

Gene expression analysis is an important tool to elucidate the complex regulatory networks of the genetic, signalling and metabolic pathway mechanisms during plant life cycle. qRT-PCR is an ideal tool to verify the results of differential gene expression of interest on a smaller scale. To study mRNA expression levels, a set of appropriate reference genes are fundamental to get reliable results from qRT-PCR. In this study, thirty-nine genes annotated as $18 S$ rRNA (18S ribosomal RNA), CYP (cytochrome), Actin, GAPDH (glyceraldehyde-3-phosphate dehydroge-

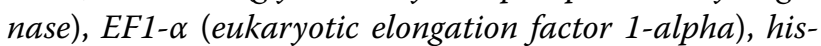
tone, TUA (alpha-tubulin), TUB (beta-tubulin), UBQ (ubiquitin) and $U B C$ (ubiquitin-conjugating enzyme) were selected as candidate reference genes to evaluate their expression stability in different pitaya tissues, temperature stresses and fruit developmental stages using three available statistical algorithms i.e. geNorm [6], NormFinder [18] and BestKeeper [19]. The aim of the present study is to identify appropriate reference genes for qRT-PCR normalization in pitaya and facilitate future molecular studies in Hylocereus. In addition, we validated the expression levels of the key genes related to betalain biosynthesis using the selected reference genes.

\section{Materials and methods \\ Plant materials}

Two pitaya cultivars i.e. Guanhuahong (H. monacanthus) and Guanhuabai (H. undatus) pitayas from the same orchard of Dalingshan Forest Park were used as plant materials. Guanhuahong pitaya is a red flesh fruit with red peel while Guanhuabai pitaya is a white flesh fruit with red peel (Additional file 1: Fig. S1). Root, stem, receptacle, calyx, petal, filament, anther, ovary, style, stigma, peel and flesh were collected separately and used for expression analyses of candidate reference genes. Pitaya flesh were collected on the 13rd, 16th, 19th, 23rd, 25th, 27th and 29th days after flowering (DAF) in July and August, 2015 (Additional file 1: Fig. S1). Cutting seedlings were collected for expression analyses of candidate reference genes on the 0,9 th, 18th, 36th, 72th and 144th $\mathrm{h}$ after cultivating in different temperature stresses $\left(4{ }^{\circ} \mathrm{C}, 10^{\circ} \mathrm{C}\right.$ and $\left.25^{\circ} \mathrm{C}\right)$. All samples were immediately frozen in liquid nitrogen and stored at $-80^{\circ} \mathrm{C}$ until use.

\section{Candidate gene selection and primer design}

Thirty-nine candidate reference genes with relatively stable expression levels (based on reported RPKM and fold change values) i.e. $18 S$ rRNA, $\operatorname{Actin}(1), E F 1-\alpha(1), E F 1$ $\alpha(2), E F 1-\alpha(3), E F 1-\alpha(4), E F 1-\alpha(5), G A P D H, \operatorname{Actin}(2)$, $\operatorname{Actin}(3), \operatorname{Actin}(4), T U A(1), T U A$ (2), CYP(1), CYP(2), eIF(1), $\operatorname{IIF}(2), \operatorname{eIF}(3), \operatorname{eIF}(4), \operatorname{eIF}(5)$, histone(1), histone(2), histone(3), histone(4), histone(5), TATA(1), TATA(2), TATA(3), $U B C(1), U B C(2), U B C(3), U B C(4), U B C(5)$, $U B C(6), T U B(1), T U B(2), U B Q(1), U B Q(2)$ and $U B Q(3)$ were selected from pitaya transcriptome database (NCBI accessions: SRR2924904) (Additional file 2: Table S1) [23]. The specific primers (Table 1) were designed using Primer Premier 5.0 with the following parameters: melting temperature $(\mathrm{Tm})$ values ranging from 47 to $63{ }^{\circ} \mathrm{C}$, GC percent of $25-65 \%$, primer lengths of $18-22 \mathrm{bp}$ and product length of 100-300 bp. Tenfold serial dilutions of cDNA were used to determine slope of the standard curve to calculate amplification efficiency of primer $\left(\mathrm{E}=10^{(-1 / \text { slope of the standard curve })}\right)$.

\section{RNA extraction and CDNA synthesis}

Total RNA was extracted according to the protocol of Wu et al. [24] and was purified by RNase-free columns (Huayueyang, Beijing, China). Genomic DNA was 
Table 1 Primers used in this study

\begin{tabular}{|c|c|c|c|c|}
\hline Genes & Forward primer $\left(5^{\prime}-3^{\prime}\right)$ & Reverse primer $\left(5^{\prime}-3^{\prime}\right)$ & Length (bp) & Efficiency (\%) \\
\hline 185 rRNA & TGCTTTGAGCACTCTAATTT & CTTGGGTCGTAAGGGTCGGT & 140 & 90.1 \\
\hline $\operatorname{Actin}(1)$ & AAAGGCTAACAGGGAGAAAA & GACCACTGGCGTAAAGAGAA & 104 & 107.9 \\
\hline $\operatorname{Actin}(2)$ & AAACTAGGAAGGAGAAAGGA & AAATAGAGAGCATACAGGGC & 230 & 94.3 \\
\hline $\operatorname{Actin}(3)$ & GCTTTTCCTTGATGTCTCTC & TCCTGCCATGTATGTTGCTA & 260 & 103.4 \\
\hline $\operatorname{Actin}(4)$ & GAAAACGGATGGGAGGAGAA & GCTGATAGAATGAGCAAGGA & 238 & 94.9 \\
\hline CYP(1) & GTGCCCAAAACAGCAGAAAA & ATCCCCCAGAGTGAAATCCC & 150 & 95.9 \\
\hline CYP(2) & GGGTTCAGTAGGAGGGATTT & CTCAGCAGTTTTCGGGGTAA & 140 & 106.3 \\
\hline$E F 1-a(1)$ & CGAAGGCACAGAAATACCGT & GCTTTTTAACCCATCCAAATG & 288 & 108.5 \\
\hline$E F 1-a(2)$ & AGGTTCTCCACTCAGGCAAC & ACACTCCGCACAATCTCTTC & 260 & 99.4 \\
\hline$E F 1-a(3)$ & TCACACGGGAAGAGGGAAAG & AGGGTATAGCAGCCAGGAAC & 290 & 96.3 \\
\hline$E F 1-a(4)$ & GAGCACTCTTTCTCTTTTGA & GAATCTGGTTTAGTCCCTGT & 286 & 97.9 \\
\hline$E F 1-a(5)$ & AACAGGGGGAAAGGGAAAAC & TGGGGAGGAGAGGAAGGGTA & 220 & 110.4 \\
\hline $\operatorname{elF}(1)$ & TCTTCTATGGATGTATGGGG & CGTTCTTGGTGTTGAGGTTT & 114 & 100.9 \\
\hline elF(2) & CAGTGTCTTTTGTTCCGCCT & TTCCTGTGCCCCTACTTGCC & 168 & 99.5 \\
\hline elF(3) & AGGGATGGGAAGAAGGTAAC & ATTCAAAGCATTCAGGGTCA & 192 & 95.3 \\
\hline elF(4) & TCCTTAGCCTGGGATTCTTC & CCTGGTTTCTGAGTTTGCGT & 236 & 99.7 \\
\hline elF(5) & CTCAGAGACTCAGACCCACA & GACCATCCAATGAACCACCT & 218 & 98.6 \\
\hline GAPDH & GGTATGAGCAGAATAAAGCA & GGTAATCAATAACAGAACGC & 124 & 96.7 \\
\hline histone(1) & AGTCACATACACTGAGCACG & CATAACTAAACGAAGAACCA & 228 & 108.3 \\
\hline histone(2) & GGACATTTGATTAGGTTTTG & ATAGATTCTCCCTTTTTTTT & 192 & 95.9 \\
\hline histone(3) & TGTCTTTTGATTTGGTGTTT & CTCTCCATTTTCTTTTTGTG & 170 & 92.1 \\
\hline histone(4) & GAAAAGTGCTCCGAGACAAC & AACCCCCAAATCCATACAAA & 252 & 96.7 \\
\hline histone(5) & TCTCTGGAGCATGTAGAAGC & GGCAAAAACCCATAGACTGT & 226 & 91.3 \\
\hline $\operatorname{TATA}(1)$ & CATAAAGGAAGGGAGGGAGA & ATGATTACAGCAGCGAAACG & 224 & 97.5 \\
\hline TATA(2) & GTTAAATTTCCCATCAGACT & CCAGATACAAAGATAAGCAG & 134 & 99.9 \\
\hline TATA(3) & TTCTGCTACATCTGCTCTCT & TTACATTTCTTTCTGCTTCC & 246 & 101.3 \\
\hline TUA(1) & AAGGAAGATGCGGCAAATAA & GGAGGGAGTGCGTAGAGAGC & 298 & 106.4 \\
\hline TUA(2) & AGAAGGTGTTAAACGAATCA & AGGAAGAGAAAAAGAGGTAG & 180 & 98.1 \\
\hline $\operatorname{TUB}(1)$ & ATTACTCGGTTACTCCAGCC & AAAGATTCCCCTCTTCAAAA & 102 & 97.4 \\
\hline $\operatorname{TUB}(2)$ & GGTGGGAGGAGGTGGTGGTA & AGGGAGGGATTCTGAGCCGT & 158 & 93.7 \\
\hline$U B C(1)$ & TCTCGGGATAATCTTTGTCA & AGGAACTTCAGGTTGTTGGA & 196 & 105.4 \\
\hline$U B C(2)$ & TTTCCATCTGCTCGCTGTTG & GCTCCTTGCTGTGCTCTCGT & 110 & 102.1 \\
\hline$U B C(3)$ & TATTCTTTGACTTTTCGCTC & TTCCTGATGCTTATCCCTAC & 262 & 96.9 \\
\hline$U B C(4)$ & TGGCTTCCAGACAAATCAAC & GCAACCTACCTCAGCACCTT & 300 & 93.5 \\
\hline$U B C(5)$ & TATCAATCCTTCATCCGCCA & СССТТССТТАТСАТСССТСC & 182 & 99.5 \\
\hline$U B C(6)$ & GAAGTTGTCGGAGCTTGGTG & TTTTGGAGGTGAATGAGGGA & 288 & 99.6 \\
\hline$U B Q(1)$ & TCGGAAAGGAAAGTCAATTA & CTCACCCACATCAAACACAG & 256 & 105.7 \\
\hline$U B Q(2)$ & AATAGACTCAAAATAAGGCG & CCAAGAAAATGGAAGAACTG & 296 & 106.8 \\
\hline$U B Q(3)$ & TCAACCAAATAACCCCTGCG & CCTGCCTTGTGGCTCTCACC & 284 & 108.1 \\
\hline Cyt P450-like1 & GCTCCAGCCGAACCATACCC & TCTTCCTAAAACTCCGCCAT & 102 & 104.3 \\
\hline
\end{tabular}

removed by DNase I (TaKaRa, Dalian, China). RNA quality was analyzed by $1.0 \%$ agarose gel and RNA integrity was assessed using an Agilent 2100 Bioanalyzer (Agilent Technologies, Santa Clara, CA, USA). Only RNA samples with an A260/A280 ratio of 1.8-2.2 and an A260/A230 ratio $>1.8$ were used for further analysis. cDNA was synthesized from $2.0 \mu \mathrm{g}$ of total RNA samples using M-MLV first strand cDNA synthesis kit according to the manufacturer's instructions (TaKaRa).

qRT-PCR analyses

qRT-PCR was conducted with ABI 7500 real-time PCR System (Applied Biosystems, CA, USA) using the SYBR ${ }^{\circledR}$ Premix Ex Taq ${ }^{\mathrm{TM}}$ II (TaKaRa). Twenty microliters reaction 
mixture contained $2 \mu \mathrm{L}$ of diluted cDNAs $(\sim 15 \mathrm{ng} / \mu \mathrm{L})$, $10 \mu \mathrm{L}$ SYBR Premix Ex Taq II (TaKaRa), $0.4 \mu \mathrm{L}$ of each primer $(10 \mu \mathrm{M})$ and $7.2 \mu \mathrm{L} \mathrm{ddH}_{2} \mathrm{O}$. The PCR reaction conditions were as follows: $50{ }^{\circ} \mathrm{C}$ for $2 \mathrm{~min}$; $95{ }^{\circ} \mathrm{C}$ for $10 \mathrm{~min} ; 40$ cycles at $95{ }^{\circ} \mathrm{C}$ for $15 \mathrm{~s} ; 56{ }^{\circ} \mathrm{C}$ for $30 \mathrm{~s}$; and $72{ }^{\circ} \mathrm{C}$ for $40 \mathrm{~s}$. The melting curve was generated by heating the amplicon from 60 to $95{ }^{\circ} \mathrm{C}$ to confirm primer specificity. Each PCR reaction was repeated three times with three biological replicates. Relative fold changes in gene expression were calculated using the comparative $2^{-\Delta \Delta \mathrm{CT}}$ method [25].

\section{Analysis of gene expression stability}

NormFinder, geNorm and BestKeeper were used to evaluate expression stability of reference genes in various pitaya tissues, temperature stresses and fruit developmental stages. The geNorm program determines stability and the optimal number of genes required to calculate the $M$ value and pairwise variation $V n / V n+1$ between two sequential normalization factors [6]. The NormFinder program was performed to obtain the best candidate reference genes by the average expression stability between samples based on the results of variance analysis [18]. The BestKeeper program is used for determination of stable reference genes, which calculates pairwise correlations based on standard deviation (SD) and percentage covariance (Cov) values [19].

\section{Validation of reference genes}

To validate the reliability of the selected reference genes, the relative expression levels of a key gene Cytochrome P450 (Cyt P450-like1) involved in betalain biosynthesis were analyzed using qRT-PCR at different flesh coloration stages of Guanhuahong and Guanhuabai pitayas. The specific primers were designed according to Hua et al. [23] (Table 1).

\section{Statistical analyses}

Statistical analyses were performed using SPSS 17.0 software.

\section{Results}

\section{Selection of candidate reference genes and sequence} analyses

Thirty-nine reference genes from the transcriptome of pitaya were selected as putative candidate reference genes (Additional file 2: Table S1). The cDNA fragments of the 39 reference genes ranged from 234 to $5304 \mathrm{bp}$. Results from BLAST analyses demonstrated that 27 reference genes had maximum identity (80-92\%) with similar deduced polypeptides from Chenopodium quinoa, 7 reference genes had maximum identity (93 to 99\%) with similar deduced polypeptides from $H$. monacanthus, and the rest are similar to the other plants (Additional file 3: Table S2). For example, Actin(1) had 98\% sequence identity with Hpactin7 (MF356257.1), eIF(1) shared 86\% sequence identity with CqeIF6-2 (XM_021866570.1) and histone(3) showed 92\% sequence identity with Sghistone (KC415067.1) (Additional file 3: Table S2).

\section{Verification of primer specificity and stability}

Melting curve plays an important role in assessing the effects of primer specificity. As shown in Additional file 4: Fig. S2, there were only one distinctive peak for $\operatorname{Actin}(1), E F 1-\alpha(1), E F 1-\alpha(2), E F 1-\alpha(3), E F 1-\alpha(5)$, GAPDH, Actin(3), TUA(1), TUA(2), CYP(1), CYP(2), eIF(1), eIF(2), eIF(3), eIF(4), eIF(5), histone(1), histone(3), histone(4), histone(5), TATA(1), TATA(2), TATA(3), UBQ (1), $U B Q(2), U B Q(3), U B C(1), U B C(2), U B C(3), U B C(4)$, $U B C(5), U B C(6), T U B(1)$ and $T U B(2)$. Therefore, those thirty-four candidate reference genes were selected from the thirty-nine candidate reference genes according to the melting curves (Additional file 4: Fig. S2). The efficiency for each primer pair varied from $90.1 \%$ for $18 S$ $r R N A$ to $110.4 \%$ for $E F 1-\alpha(5)$ (Table 1). The sequence length ranged from 102 to $300 \mathrm{bp}$ (Table 1). Cycle threshold $(\mathrm{Ct})$ values ranged from 17.45 for GAPDH to 37 for histone(2). The boxplot provided expression levels of the 39 candidate reference genes (Additional file 5: Fig. S3). A lower $\mathrm{Ct}$ value indicated a higher gene expression levels. Across all samples, the maximum Ct values of Actin(1), $E F 1-\alpha(1), U B C(1), U B C(2), G A P D H$ and histone(1) were $<23$. GAPDH expression levels were the most variable with 5.4 Ct, while $\operatorname{Actin}(1)$ showed the least variable levels with $1.5 \mathrm{Ct}$. Based on the melting curve and $\mathrm{Ct}$ values (Additional file 4: Fig. S2 and Additional file 5: S3), six genes i.e. $\operatorname{Actin}(1), E F 1-\alpha(1), G A P D H, U B C(1), U B C(2)$ and histone(1) were selected as candidate reference genes for further analyses.

\section{$\mathrm{Ct}$ value analyses of six reference genes}

Ct values of Actin(1), EF1- $\alpha(1), G A P D H, U B C(1), U B C(2)$ and histone(1) were calculated to determine their transcript levels in different tissues, temperature stresses, fruit developmental stages of Guanhuahong and Guanhuabai pitayas. As shown in Fig. 1, a relatively wide range of transcript levels for the six reference genes were detected in different tissues, temperature stresses, fruit developmental stages of the two different color-fleshed pitaya cultivars. In different fruit developmental stages, $\mathrm{Ct}$ values of Guanhuabai and Guanhuahong pitayas ranged from 17.28 to 31.74 and 17.18 to 24.94 , respectively. Average Ct values were 21.82 for $\operatorname{Actin}(1), 21.18$ for $E F 1-\alpha(1), 20.25$ for GAPDH, 20.66 for $U B C(1), 20.96$ for $U B C(2)$ and 21.52 for histone(1), respectively (Fig. 1). The lowest $\mathrm{Ct}$ value was 17.28 for GAPDH and the highest 

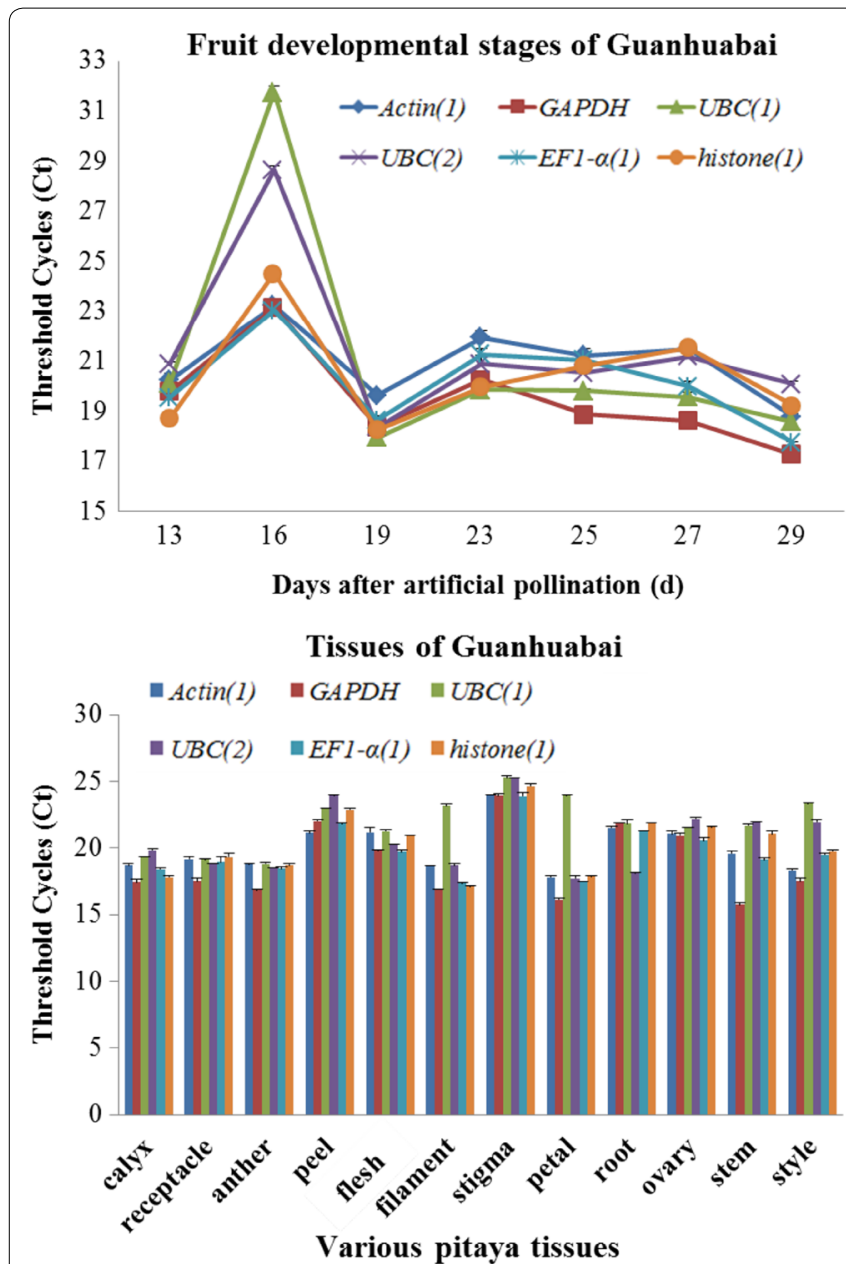

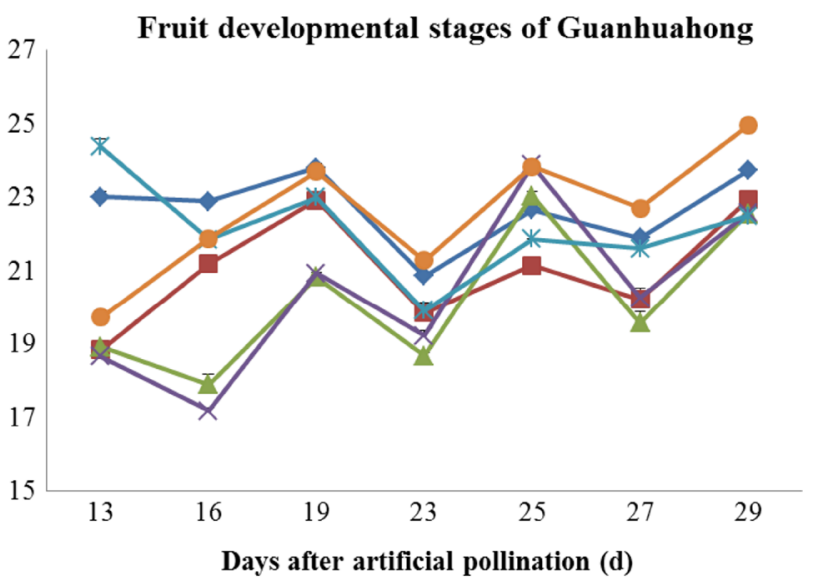

Tissues of Guanhuahong

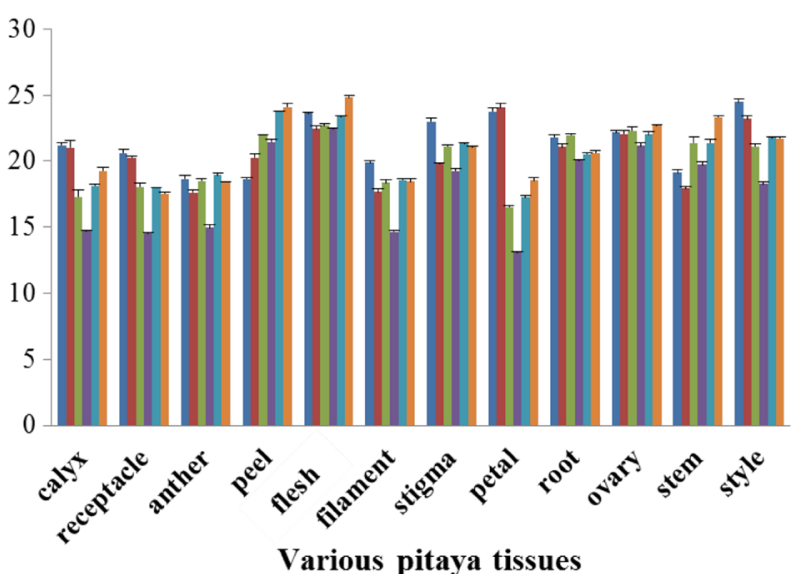

Fig. 1 Ct values of six candidate reference genes in different fruit developmental stages and tissues of pitayas. Data represent the average values from three biological replicates $( \pm S D)$

Ct value was 31.74 for $U B C(1)$ in different fruit developmental stages of Guanhuabai pitaya. As for different fruit developmental stages of Guanhuahong pitaya, the lowest $\mathrm{Ct}$ value was 17.18 for $U B C(2)$ and the highest $\mathrm{Ct}$ value was 24.94 for histone(1).

Ct values ranged from 15.76 to 25.29 and 14.53 to 24.82 in different tissues of Guanhuabai and Guanhuahong pitayas, respectively. Average $\mathrm{Ct}$ values were 20.70 for $\operatorname{Actin}(1), 20.06$ for $E F 1-\alpha(1), 19.75$ for GAPDH, 20.98 for $U B C(1), 19.23$ for $U B C(2)$ and 20.59 for histone(1), respectively (Fig. 1). The lowest $\mathrm{Ct}$ value was 15.76 for GAPDH gene and the highest $\mathrm{Ct}$ value was 25.29 for $U B C(2)$ in different tissues of Guanhuabai pitaya. The lowest $\mathrm{Ct}$ value was 14.53 for $U B C(2)$ gene and the highest Ct value was 24.82 for histone(1) gene in different tissues of Guanhuahong pitaya.

In different temperature stresses, the lowest $\mathrm{Ct}$ value was 15.92 for GAPDH and the highest Ct value was 23.74 for histone(1). Ct values ranged from 20.81 to 22.84 for
Actin(1), 17.79 to 19.78 for $E F 1-\alpha(1), 15.92$ to 19.82 for $G A P D H, 19.50$ to 21.35 for $U B C(1), 18.13$ to 19.69 for $U B C(2)$ and 19.53 to 23.74 for histone(1), respectively (Additional file 6: Fig. S4).

The coefficient of variance $(\mathrm{CV})$ of $\mathrm{Ct}$ values can determine reference gene stability levels. $U B C(2)$ presented a high degree of transcript level variation with a $C V$ value of $15.61 \%$ while $\operatorname{Actin}(1)$ presented the lowest degree of variation with a CV value of $4.96 \%$ (Additional file 7 : Table S3). Among the six candidate reference genes, Actin(1) (4.96\%) was the most stable gene while $U B C(1)$ (13.16\%) and $U B C(2)(15.61 \%)$ showed the lowest expression stability according to $\mathrm{CV}$ value analyses of six reference genes.

\section{GeNorm analysis}

GeNorm was used to select the most stable reference gene by calculating the gene expression stability measure $(\mathrm{M})$ based on the average pairwise expression ratio. 
The gene with the lowest $M$ value is considered the most stable. A gene with $\mathrm{M}$ value below 1.5 can be considered as a reference gene. As shown in Fig. 2, the $M$ values of Actin(1), EF1- $\alpha(1), G A P D H, U B C(1), U B C(2)$ and histone(1) were lower than 1.5 , suggesting that all of them conformed to basic requirements for the reference gene. Among the six genes, $U B C(2)$ was the least stable reference gene with the highest $M$ value ( $>0.214)$ detected in the two different colored pitayas, different tissues and fruit developmental stages of Guanhuahong and Guanhuabai pitayas. EF1- $\alpha(1)$ and $\operatorname{Actin}(1)$ were the most stable genes with the lowest $M$ value $(<0.058)$ in different tissues and fruit developmental stages of Guanhuabai pitayas. As for different development stages of Guanhuahong pitaya, the most stable genes were $U B C(1)$ $(\mathrm{M}=0.041)$ and $U B C(2)(\mathrm{M}=0.041)$, followed by histone(1) $(\mathrm{M}=0.078)$. UBC(1) $(\mathrm{M}=0.053)$ and $E F 1-\alpha(1)$ $(\mathrm{M}=0.053)$ showed the highest levels of expression stability for different tissues of Guanhuahong pitaya. In different temperature stresses, the most stable genes were $\operatorname{Actin}(1)(\mathrm{M}=0.040)$ and $U B C(1)(\mathrm{M}=0.040)$. Actin(1) $(\mathrm{M}=0.119)$ and $E F 1-\alpha(1)(\mathrm{M}=0.119)$ are the most stable reference gene suitable for transcript normalization in all tissues/fruits between the two cultivars. Concerning all samples of tested, Actin(1) was the best reference gene for qRT-PCR normalization.

A single reference gene often can not meet the requirements of accurate quantification for transcription analyses of gene expression. It is necessary to use two or more than two reference genes to produce accurate and reliable normalization. The optimal number of reference genes can be determined using the pairwise variation value $(\mathrm{Vn} / \mathrm{Vn}+1, \mathrm{~V}$-value) as normalization factor for reference genes. Additional $(n+1)$ reference genes are necessary to normalize the genes if $\mathrm{V}$-value is higher than the threshold of 0.15. As shown in Fig. 3, the pairwise variation values of reference genes were examined when all samples were considered. The ratio of V2/V3 was lower than the threshold of 0.15 , suggesting that the optimum number of reference gene was two. There is no need to add a third reference gene as an internal control for the normalization of gene expression in pitaya. Therefore, a combination of Actin(1) and EF1- $\alpha(1)$ was the optimum

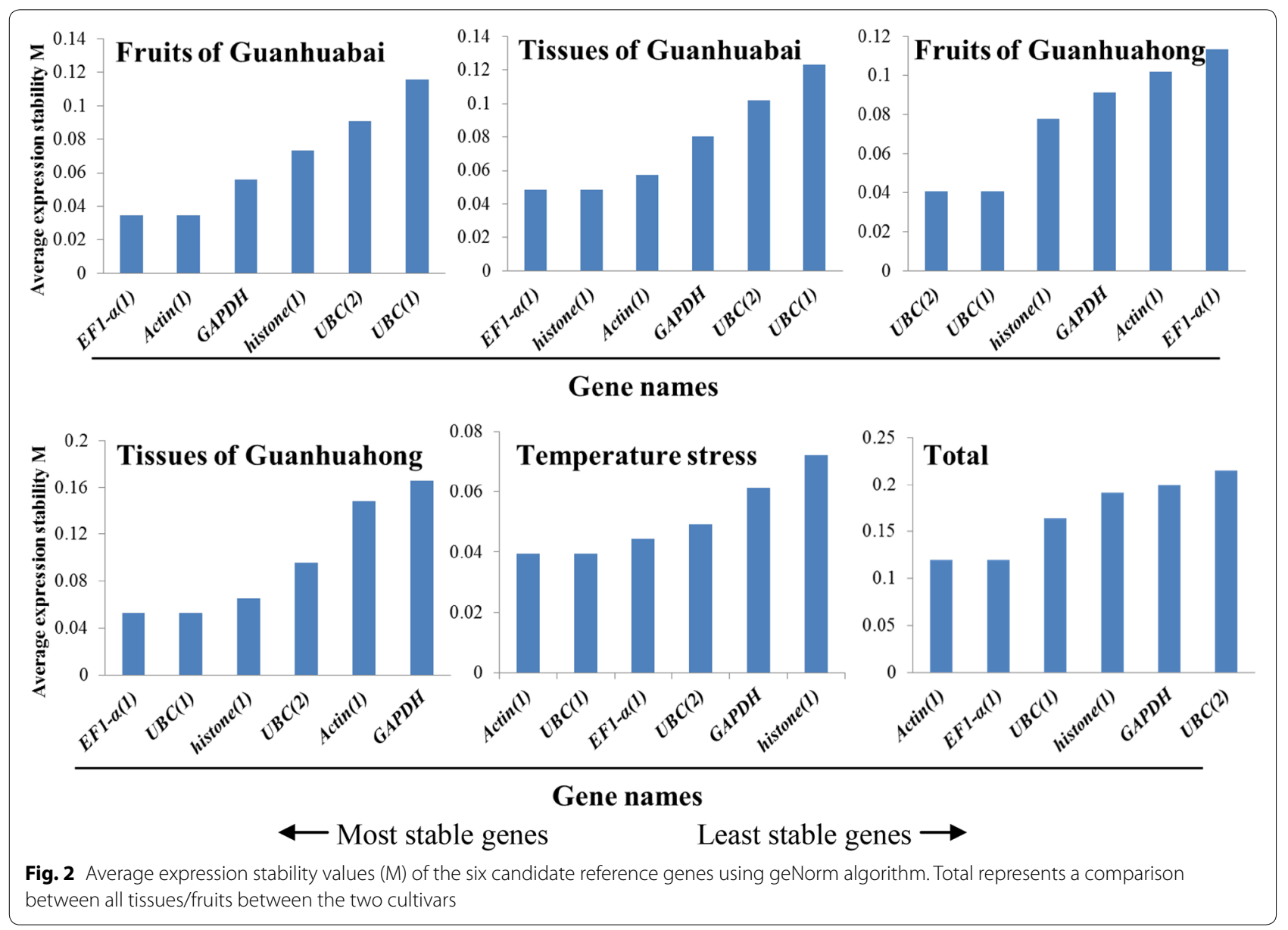




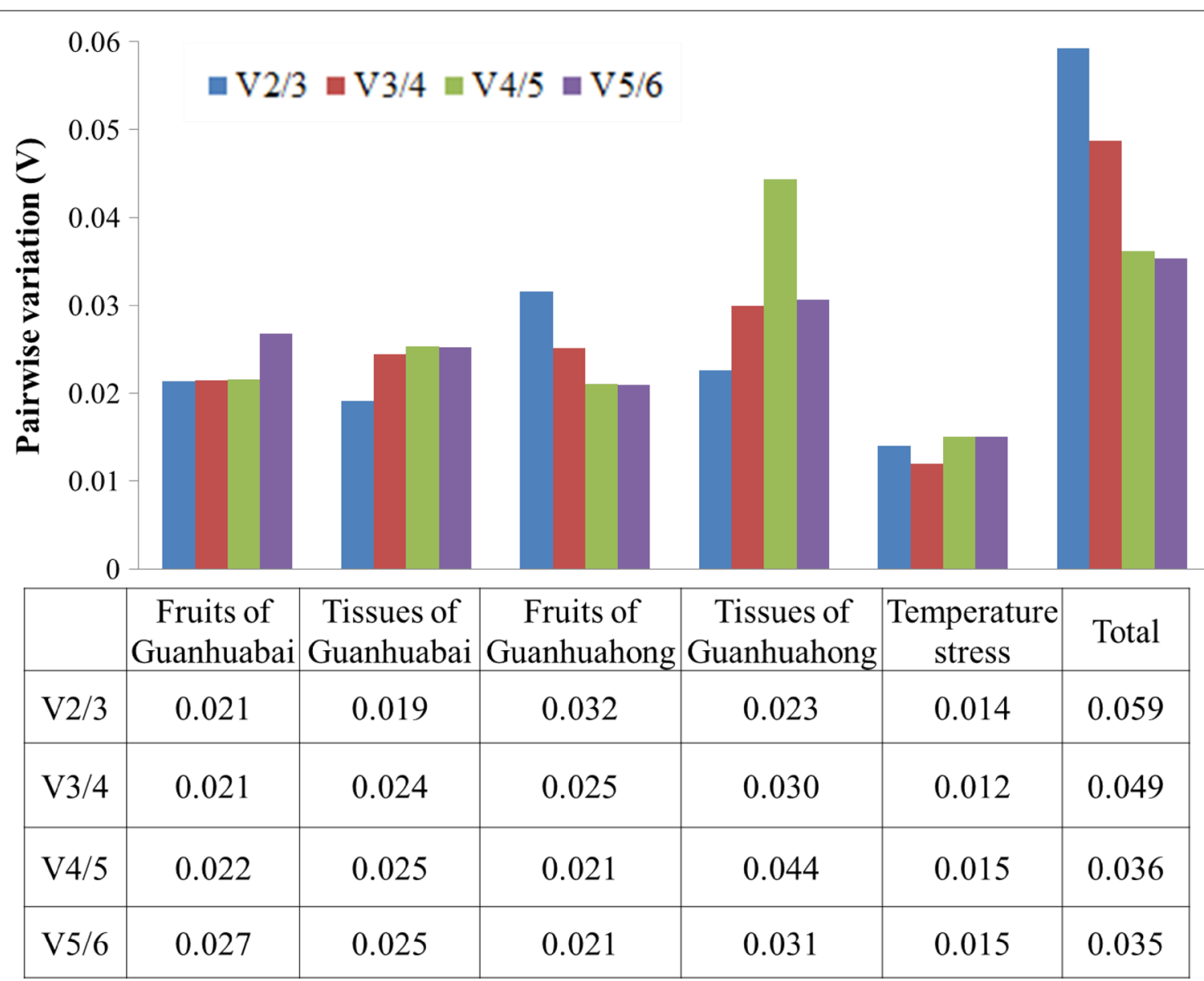

Fig. 3 Pairwise variation (V) analyses of the six candidate reference genes using geNorm algorithm. Total represents a comparison between all tissues/fruits between the two cultivars

reference genes for qRT-PCR normalization of various samples in pitaya.

\section{NormFinder analysis}

Different from geNorm, the NormFinder can determinate optimal number of reference genes for normalization by intra- and inter- group variations. Average gene expression stability values of the six reference genes in different samples were calculated by NormFinder software and ranking was made based on relative stability values. As shown in Fig. 4, $U B C(1)$ was the least stable reference gene in the total dataset, which is different from the result obtained by NormFinder. In different fruit developmental stages, GAPDH and histone(1) emerged as the most stably expressed gene for Guanhuabai pitaya compared with $U B C(1)$ and $G A P D H$ for Guanhuahong pitayas. In various tissues of Guanhuabai and Guanhuahong pitayas, $E F 1-\alpha(1)$ was the most stable reference gene. $U B C(1)$ and Actin(1) were the best reference gene for different temperature stresses. Combined with expression analyses of all samples, histone(1) and GAPDH were the most stable reference genes for normalization in pitaya.

\section{BestKeeper analysis}

BestKeeper program was used to grade candidate reference gene stability by calculating $\mathrm{SD}$ of the Ct values, $\mathrm{CV}$ and pair correlation coefficient. A gene with $\mathrm{SD}$ value below 1.0 can be considered as stable expression. In different temperature stresses, $\mathrm{SD}$ values were 0.38 for $U B C(2), 0.42$ for $U B C(1), 0.44$ for $E F 1-\alpha(1), 0.47$ for Actin(1), 0.59 for GAPDH and 1.08 for histone(1), respectively. As for the different fruit developmental stages of Guanhuahong pitaya, SD values of Actin(1) and EF1- $\alpha$ (1) were 0.76 and 0.97 , respectively, suggesting $\operatorname{Actin}(1)$ and $E F 1-\alpha(1)$ could be used as reference genes. Actin(1) was the most stably expressed gene, followed by EF1- $\alpha(1)$ (Fig. 5). Compared with Guanhuabai pitaya, Actin(1) was the most stable gene for normalization of the different fruit developmental stages of Guanhuahong pitaya. In different tissues of Guanhuabai and Guanhuahong 


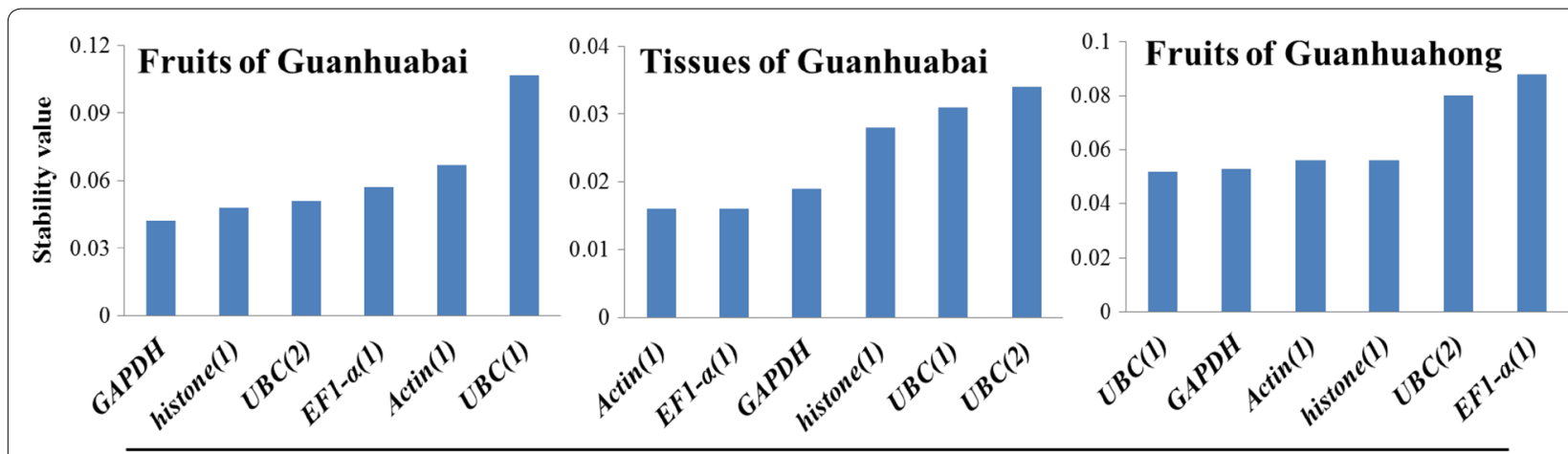

Gene names
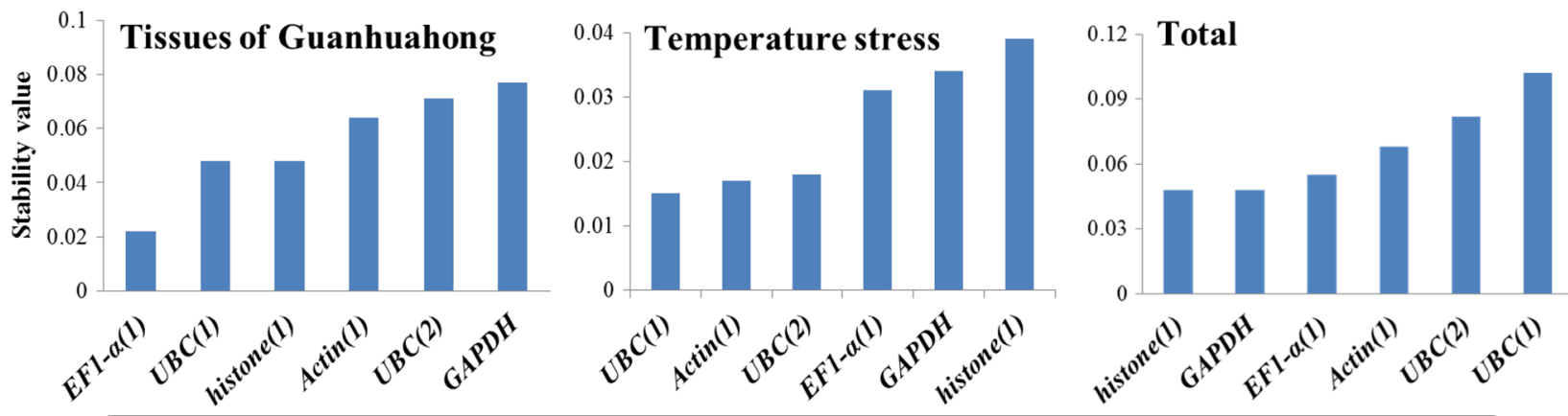

Gene names

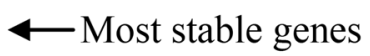

Least stable genes $\rightarrow$

Fig. 4 Expression stability values and ranking of the six candidate reference genes using NormFinder algorithm. Total represents a comparison between all tissues/fruits between the two cultivars

pitayas, $E F 1-\alpha(1)$ (0.97) and $\operatorname{Actin}(1)$ (0.9) was the most stable gene, respectively; $U B C(2)$ (2.58) was the least stable reference gene with the highest SD value. In the different colored pitayas, $\operatorname{Actin}(1)$ (0.97) was considered to be the most stable gene. Taking into account the total dataset, $\operatorname{Actin}(1)$ was the most stable gene in all samples tested. The results of BestKeeper were consistent with the analyses of geNorm.

\section{Reference genes validation}

To validate the suitability of the two selected reference genes $(\operatorname{Actin}(1)$ and $E F 1-\alpha(1))$, and the least suitably ranked candidates $U B C(2)$ according to BestKeeper and geNorm analyses. Relative expression levels of a key gene Cyt P450-like1 involved in betalain biosynthesis were evaluated using qRT-PCR at different flesh coloration stages of Guanhuahong (H. polyrhizus) and Guanhuabai (H. undatus) pitayas (Fig. 6). The expression levels of Cyt P450-like1 increased gradually during flesh color transition from white ( 23 days) to red stages (25 days) and decreased at full maturation stage (29 days) when single or a combination of reference genes $(\operatorname{Actin}(1)$ and
EF1- $\alpha(1))$ were used for normalization. These results were in accordance with betalain accumulation pattern and expression characteristics of Cyt P450-like1 gene related to betalain biosynthesis at all flesh coloration stages of $H$. monacanthus $[23,26]$. However, the expression pattern of Cyt P450-like1 normalized by $U B C(2)$ increased gradually at all flesh coloration stages of Guanhuahong pitaya. Furthermore, when $U B C(2)$ was used to normalize $C y t$ P450-like1 expression in Guanhuabai pitaya, the expression values of 23 days were overestimated. In general, the RT-qPCR profiling of Cyt P450-like1 gene expression supported the analyses of BestKeeper and geNorm .

\section{Discussion}

qRT-PCR is the most sensitive technology of measuring gene transcript levels depending on stable reference gene(s) for normalization [27]. An appropriate reference gene can effectively correct the errors of RNA quantity, reverse transcription efficiency, stability of different reaction channels of PCR instrument and standard operation mode, which can help to obtain the real differential expression of the target genes [28]. The reference genes 


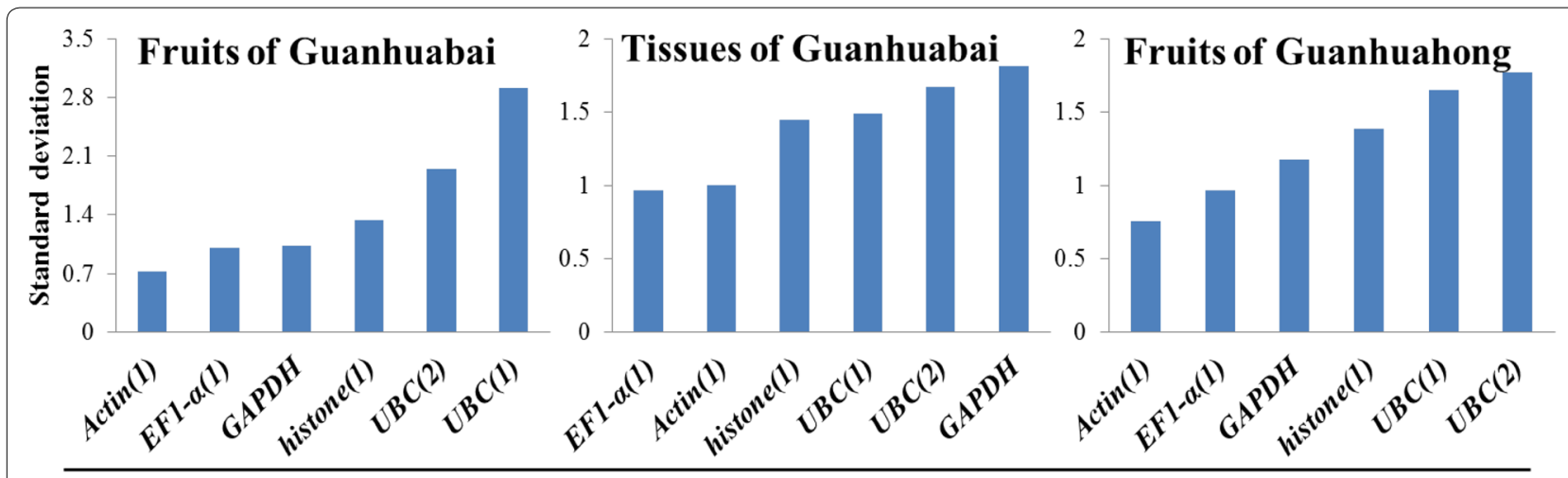

Gene names

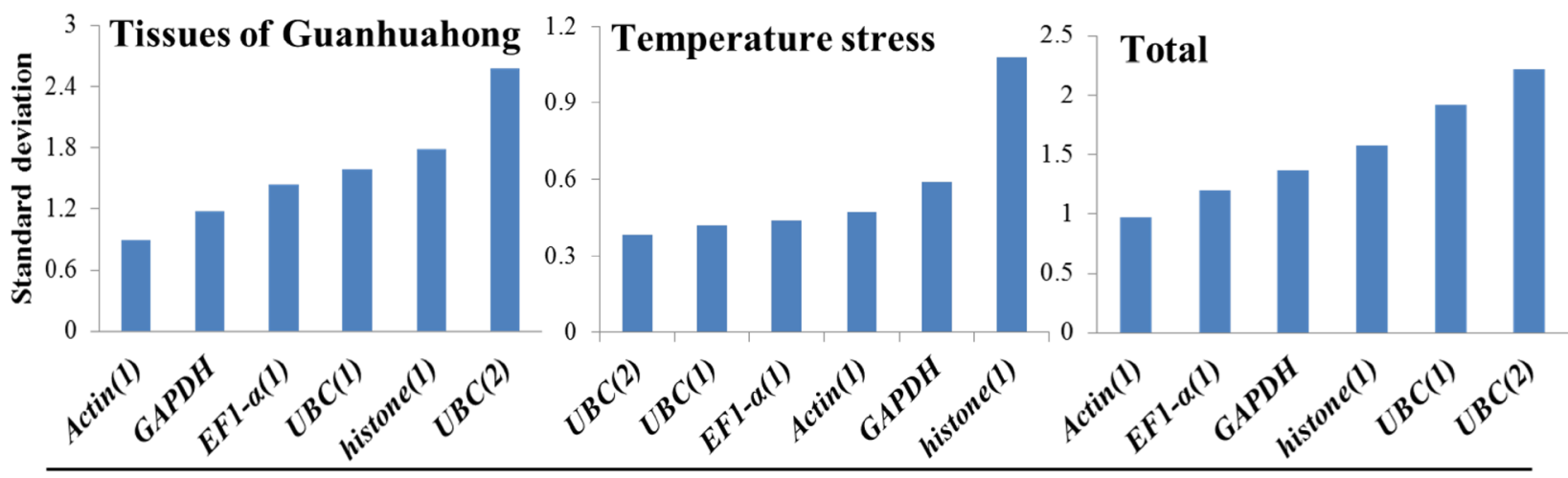

Gene names

$\longleftarrow$ Most stable genes $\quad$ Least stable genes $\longrightarrow$

Fig. 5 Expression stability values and ranking of the six candidate reference genes using BestKeeper algorithm. Total represents a comparison between all tissues/fruits between the two cultivars

such as Actin, $18 S$ rRNA and GAPDH are commonly used as reference genes. However, these reference genes show instability in various plant species or genotypes $[13,14,29]$. Their expression levels are different in different patterns of cells and tissues, physiological status and growth periods [30,31]. Therefore, it is essential to select the most suitable reference gene for the specific sample types and experimental conditions. Pitaya has become a popular fruit due to its excellent nutritional, commercial and medical values [20-22]. To date, there is no report on the identification of the most suitable reference gene in pitaya. In this study, 39 typical reference genes from pitaya transcriptome database [23] were selected to determine the most stable reference gene for qRT-PCR normalization in pitaya. Based on the melting curve and $\mathrm{Ct}$ values of reference genes (Additional file 4: Fig. S2 and Additional file 5: S3), six genes, i.e. Actin(1), EF1- $\alpha(1)$, $G A P D H, U B C(1), U B C(2)$ and histone(1) were selected as candidate reference genes for further analyses.
NormFinder [18], geNorm [6] and BestKeeper [19] were commonly used to evaluate the stability of the reference genes. The geNorm was applied to estimate the stability of a candidate gene by pairwise comparison, while the NormFinder and BestKeeper were used to prevent co-regulation and to further assess the results obtained by the geNorm program. In the present study, geNorm, NormFinder and BestKeeper were applied to define the stability of Actin(1), EF1- $\alpha(1), G A P D H$, $U B C(1), U B C(2)$ and histone(1) reference genes in different tissues, temperature stresses and fruit developmental stages of pitaya. Different rankings for the six candidate reference genes were detected after comparison to the ranking of the candidates generated by the three algorithms (Fig. 2, 3, 4, 5). From the geNorm evaluation, we found that $\operatorname{Actin}(1)$ and $E F 1-\alpha(1)$ were the optimum reference genes for qRT-PCR normalization of various samples of pitaya. The results of BestKeeper were consistent with the analyses of geNorm, showed 


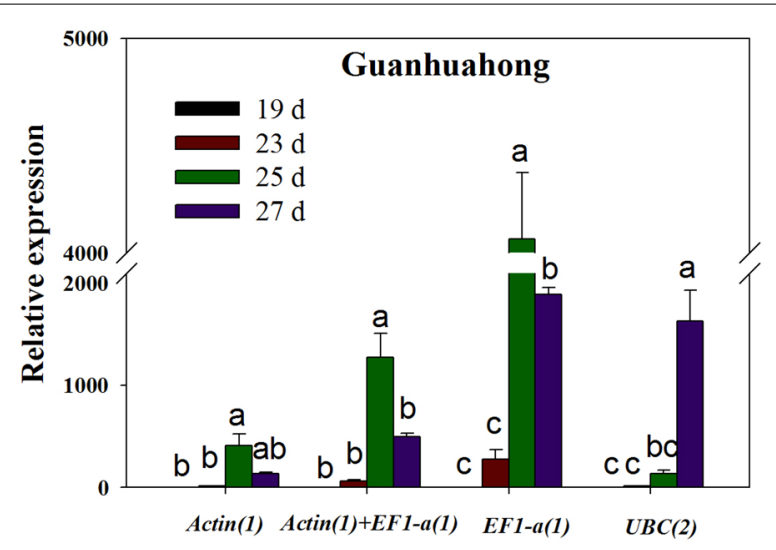

Gene names

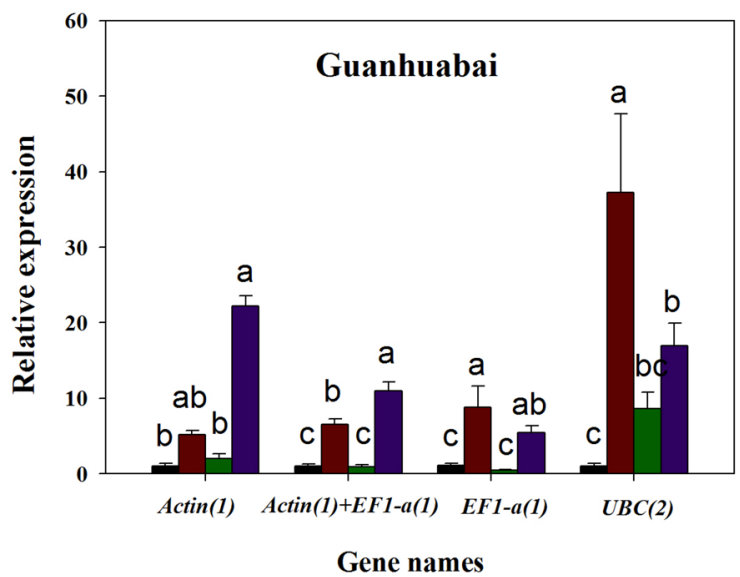

Fig. 6 Relative expression of cyt P450-like1 in Guanhuahong and Guanhuabai pitayas. Actin (1), EF1-a(1) and Actin(1) +EF1-a(1) were used as one or two most stable reference genes, $U B C(2)$ was used as the least stable reference gene. Different letters indicate significant difference of the expression of the target gene based on three biological replications $(P<0.05, \mathrm{t}$ test; $\mathrm{n}=3)$

that $\operatorname{Actin}(1)$ was the most stable reference gene in all of the samples examined. However, results from NormFinder analyses showed that histone(1) and GAPDH were the most stable reference genes in all of the samples tested. The reason for the differences in the topranked reference genes may be due to the discrepancies resulted from different approaches of calculations by geNorm, NormFinder and BestKeeper programs. Similar results were also obtained in Vitis vinifera [32], Citrus [33], Euscaphis konishii [34], Cowpea [35] and Actinidia deliciosa [36]. It has been reported that the most discrepant results in gene stability ranking were obtained by BestKeeper [37]. In our study, although there are some differences in the stability of each reference gene expression of samples from the three different algorithms, $\operatorname{Actin}(1)$ and $E F 1-\alpha(1)$ are the optimum reference genes. Combining the three algorithms with expression analyses, we suggested $\operatorname{Actin}(1)$ was the most adequate reference gene for expression studies in different tissues, temperature stresses and fruit developmental stages of pitaya.

Cytochrome P450 is a key gene involved in betalain biosynthesis [23, 38-42]. To validate the candidate reference genes, the relative expression levels of Cyt P450like1 gene were analyzed by qRT-PCR during flesh coloration of Guanhuabai and Guanhuahong pitayas. Expression levels of Cyt P450-like1 increased gradually during flesh coloration and decreased at full maturation stage when single or a combination of reference genes (Actin(1) and EF1- $\alpha(1))$ were used as reference genes. Those results were in consistent with betalain accumulation pattern and expression characteristics of Cyt P450-like1 at all flesh coloration stages of H. monacanthus. Moreover, the expression pattern of Cyt P450like1 increased with fruit maturation of $H$. undatus $[23,24]$. Those results suggested that $\operatorname{Actin}(1)$ was the most stable reference gene for expression studies of key genes involved in betalain biosynthesis of pitaya. And the most stable reference gene combination for expression studies in pitaya was $\operatorname{Actin}(1)$ and $E F 1-\alpha(1)$.

\section{Conclusions}

To the best of our knowledge, this study is the first report on systematically evaluating the expression stability of different potential reference genes for qRT-PCR in the Cactaceae family. Thirty-nine typical reference genes were selected to determine the most stable reference genes for qRT-PCR normalization in pitaya. Based on the melting curve and Ct values, Actin(1), EF1- $\alpha(1)$, $G A P D H, U B C(1), U B C(2)$ and histone(1) genes were selected for further analyses in different tissues, temperature stresses and fruit developmental stages of pitayas. Actin(1) and EF1- $\alpha(1)$ were identified as the optimum internal control genes according to calculations made with geNorm, NormFinder and BestKeeper programs. Validation of suitable reference genes was carried out to profile the expression of Cyt P450-like1 gene during flesh coloration stages of Guanhuahong and Guanhuabai. Actin(1) was the best reference gene for qRT-PCR normalization. The present study provides the appropriate reference gene for normalization of reliable qRT-PCR data in different pitaya tissues, temperature stresses and fruit developmental stages which will be useful for the expression profiles of target genes in Hylocereus plant and related species. 


\section{Additional files}

Additional file 1: Fig. S1. Different fruit developmental stages of Guanhuabai (A) and Guanhuahong (B) pitayas. A1 and B1, 13 days; $A 2$ and B2, 16 days; $A 3$ and $B 3,19$ days; $A 4$ and $B 4,23$ days; $A 5$ and $B 5,25$ days; $A 6$ and $B 6,27$ days; $A 7$ and $B 7,29$ days. $B a r=4.0 \mathrm{~cm}$.

Additional file 2: Table S1. cDNA sequences of thirty-nine reference genes.

Additional file 3: Table S2. Sequence analyses of thirty-nine reference genes.

Additional file 4: Fig. S2. Melt curve analyses of thirty-nine reference genes from eight different tissues (including roots, stems, flowers, and fruits) of Hylocereus.

Additional file 5: Fig. S3. Boxplot analyses of thirty-nine reference genes from eight different tissues (including roots, stems, flowers and fruits) of Hylocereus. The whisker caps show the distribution of the highest and lowest $\mathrm{Ct}$ values. The boxes indicate the first and third quartile, while the middle line marks the median.

Additional file 6: Fig. S4. Ct value of six candidate reference genes in different temperature stresses of pitaya cutting plantlets.

Additional file 7: Table S3. The coefficient of variance (CV) of the six candidate reference genes using BestKeeper algorithm.

\section{Abbreviations}

CAM: crassulacean acid metabolism; CDNA: complementary DNA; Cov: covariance; Ct: cycle threshold; CV: coefficient of variance; DNase I: deoxyribonuclease I; EF1-a: eukaryotic elongation factor 1-alpha; elF: eukaryotic initiation factor; GAPDH: glyceraldehyde-3-phosphate dehydrogenase; SD: standard deviation; TATA: TATA box binding protein-associated factor; TUA: alpha-tubulin; TUB: beta-tubulin; UBC: ubiquitin-conjugating enzyme; UBQ: ubiquitin.

\section{Acknowledgements}

The authors would also like to thank fellow members of the orchard of Dalingshan Forest Park for management of experimental materials.

\section{Authors' contributions}

C.C., J.W. and Y.Q. conceived and designed the experiments. C.C. and J.W. performed the experiments. C.C., J.W. and Q.H. analyzed the data. N.T., F. X., Z. Z., J.C., R.Z., G.H. and J.Z. contributed reagents/materials/analysis tools. C.C., J.W., N.T. and Y.Q. wrote and revised the paper. All authors read and approved the final manuscript.

\section{Funding}

This work was supported by the Key Areas of Science and Technology Planning Project of Guangdong Province (2018B020202011), the Key Science and Technology Planning Project of Guangzhou (201904020015), Science and Technology Program of Guangzhou (201704020003 and 2014Y2-00164), YangFan Innovative and Entepreneurial Research Team Project (2014YT02H013), and the Earmarked Fund for Guangdong Modern Agro-industry Technology Research System (2016LM1130), and the Science and Technology Planning Project of Guangdong Province (2014B020202010).

\section{Availability of data and materials}

The data and materials supporting the conclusions of this study are included within the article.

\section{Ethics approval and consent to participate}

Not applicable.

\section{Consent for publication}

All authors have consented to this publication.

\section{Competing interests}

The authors declare that they have no competing interests.

\section{Author details}

${ }^{1}$ State Key Laboratory for Conservation and Utilization of Subtropical Agro-bioresources/Guangdong Provincial Key Laboratory of Postharvest Science of Fruits and Vegetables/Key Laboratory of South China Horticultural Crop Biology and Germplasm Enhancement, Ministry of Agriculture, College of Horticulture, South China Agricultural University, Guangzhou 510642, China. ${ }^{2}$ French Associates Institute for Agriculture and Biotechnology of Drylands, The J. Blaustein Institutes for Desert Research, Ben-Gurion University of the Negev, 84990 Sede Boger, Israel.

Received: 4 December 2018 Accepted: 1 July 2019

Published online: 08 July 2019

\section{References}

1. Mackay IM. Real-time PCR in the microbiology laboratory. Clin Microbiol Infect. 2004:10:190-212.

2. Ransbotyn $\mathrm{V}$, Reusch TBH. Housekeeping gene selection for quantitative real-time PCR assays in the seagrass Zostera marina subjected to heat stress. Limnol Oceanogr Methods. 2006;4:367-73.

3. Yoo WG, Kim TI, Li SY, Kwon OS, Cho PY, Kim TS, Kim K, Hong SJ. Reference genes for quantitative analysis on Clonorchis sinensis gene expression by real-time PCR. Parasitol Res. 2009;104:321-8.

4. Reddy DS, Bhatnagar-Mathur P, Cindhuri KS, Sharma KK. Evaluation and validation of reference genes for normalization of quantitative real-time PCR based gene expression studies in peanut. PLoS ONE. 2013;8:e78555.

5. Wu WK, Liu CQ, Zhou ZG, Lu S. The selection of reference genes in Chlamydomonas reinhardtii P.A. dangeard by real-time quantitative PCR. Plant Physiol Commun. 2009;45:667-72

6. Vandesompele J, De Preter K, Pattyn F, Poppe B, Van Roy N, De Paepe A, Speleman F. Accurate normalization of real-time quantitative RT-PCR data by geometric averaging of multiple internal control genes. Genome Biol. 2002;3:1-11.

7. Shin R, Schachtman DP. Hydrogen peroxide mediates plant root cell response to nutrient deprivation. Proc Natl Acad Sci. 2004;101:8827-32.

8. Li L, Xu J, Xu ZH, Xue HW. Brassinosteroides stimulate plant tropisms through modulation of polar auxin transport in Brassica and Arabidopsis. Plant Cell. 2005;17:2738-53.

9. Jeong YM, Mun JH, Lee I, Woo JC, Hong CB, Kim SG. Distinct roles of the first introns on the expression of Arabidopsis profilin gene family members. Plant Physiol. 2006;140:196-209.

10. Sun ML, Wang YS, Yang DQ, Wei CL, Gao LP, Tao X, Shan Y, Luo Y. Reference genes for real-time fluorescence quantitative PCR in Camellia sinensis. Chin Bull Bot. 2010;45:579-87.

11. Su XJ, Fan BG, Yuan LC, Cui XN, Lu SF. Selection and validation of reference genes for quantitative RT-PCR analysis of gene expression in Populus trichocarpa. Chin Bull Bot. 2013;48:507-18.

12. Wei YD, Chen Y, Guo HP, Xie HA, Zhang JF, Wang ZH. Selection of reference genes for real-time quantitative RT-PCR in rice (Oryza sativa L. ssp. japonica) under nutrient deficiency. J Agric Biotechnol. 2013;21:1302-12.

13. Wang HB, Wang JJ, Jiang JF, Chen SM, Guan ZY, Liao Y, Chen FD. Reference genes for normalizing transcription in diploid and tetraploid Arabidopsis. Sci Rep. 2014:4:6781.

14. Wang JX, Zhang $\sqcup$, Liao ZY, Zhang YG, Qiu QD, Sun P, Sun YH, Hu RY, Lu N, LiY. The selection of reference genes for real-time quantitative PCR normalization in Black locust (Robinia pseudoacacia). Sci Silvae Sin. 2014;50:167-72.

15. Xiao XL, Ma JB, Wang JR, Wu XM, Li PB, Yao YN. Validation of suitable reference genes for gene expression analysis in the halophyte Salicornia europaea by real-time quantitative PCR. Front Plant Sci. 2015:5:788.

16. Bustin SA, Benes V, Garson JA, Helleman J, Huggett J, Kubista M, Mueller R, Nolan T, Pfaffl MW, Shipley GL, et al. The MIQE guidelines: minimum information for publication of quantitative real-time PCR experiments. Clin Chem. 2009;55:611-22.

17. Wang YJ, Dong L, Zhang C, Wang XQ. Reference gene selection for realtime quantitative PCR normalization in tree Peony (Paeonia suffruticosa Andr.). J Agric Biotechnol. 2012;20:521-8.

18. Andersen $C L$, Jensen $J$, Ørntoft TF. Normalization of real-time quantitative reverse transcription-PCR data: a model-based variance estimation 
approach to identify genes suited for normalization, applied to bladder and colon cancer data sets. Cancer Res. 2004;64:5245-50.

19. Pfaffl MW, Tichopad A, Prgomet C, Neuvians TP. Determination of stable housekeeping genes, differentially regulated target genes and sample integrity: BestKeeper-Excel-based tool using pair-wise correlations. Biotechnol Lett. 2004;26:509-15.

20. Adnan L, Osman A, Hamid AA. Antioxidant activity of different extracts of red pitaya (Hylocereus polyrhizus) seed. Int J Food Prop. 2011;14:1171-81.

21. Esquivel P, Stintzing FC, Carle R. Comparison of morphological and chemical fruit traits from different pitaya genotypes (Hylocereus sp.) grown in Costa Rica. J Appl Bot Food Qual. 2007;81:7-14.

22. Song H, Chu Q, Yan F, Yang Y, Han W, Zheng X. Red pitaya betacyanins protects from diet-induced obesity, liver steatosis and insulin resistance in association with modulation of gut microbiota in mice. J Gastroenterol Hepatol. 2016;31:1462-9.

23. Hua QZ, Chen CJ, Chen Z, Chen PK, Ma YW, Wu JY, Zheng J, Hu GB, Zhao JT, Qin YH. Transcriptomic analysis reveals key genes related to betalain biosynthesis in pulp coloration of Hylocereus polyrhizus. Front Plant Sci. 2016;6:1179.

24. Wu JY, Peng G, Li CQ, Lu WJ, Wang ZH, Li JG. A new rapid and effective method for RNA isolation from litchi tissues of fruitlet and abscission zone. Acta Hortic Sin. 2011;38:1191-6.

25. Livak KJ, Schmittgen TD. Analysis of relative gene expression data using real-time quantitative PCR and the $2^{-\Delta \Lambda C T}$ method. Methods. 2001;25:402-8.

26. Hua QZ, Chen CB, Tel Zurb N, Wang HC, Wu JY, Chen JY, Zhang ZK, Zhao $J T$, Hu GB, Qin YH. Metabolomic characterization of pitaya fruit from three red-skinned cultivars with different pulp colors. Plant Physiol Biochem. 2018;126:117-25.

27. Nicot N, Hausman JF, Hoffmann L, Evers D. Housekeeping gene selection for real-time RT-PCR normalization in potato during biotic and abiotic stress. J Exp Bot. 2005;56:2907-14.

28. Udvardi MK, Czechowski T, Scheible WR. Eleven golden rules of quantitative RT-PCR. Plant Cell. 2008;20:1736-7.

29. Wang HB, Chen SM, Jiang JF, Zhang F, Chen FD. Reference gene selection for cross-species and cross-ploidy level comparisons in Chrysanthemum spp. Sci Rep. 2015;5:8094.

30. Lee PD, Sladek R, Greenwood CM, Hudson TJ. Control genes and variability: absence of ubiquitous reference transcripts in diverse mammalian expression studies. Genome Res. 2002;12:292-7.

31. Huggett J, Dheda K, Bustin S, Zumla A. Real-time RT-PCR normalization; strategies and considerations. Genes Immun. 2005;6:279-84.
32. Reid KE, Olsson N, Schlosser J, Peng F, Lund ST. An optimized grapevine RNA isolation procedure and statistical determination of reference genes for real-time RT-PCR during berry development. BMC Plant Biol. 2006;6:27.

33. Mafra V, Kubo KS, Alves-Ferreira M, Ribeiro-Alves M, Stuart RM, Boava LP, Rodrigues CM, Machado MA. Reference genes for accurate transcript normalization in Citrus genotypes under different experimental conditions. PLoS ONE. 2012;7:e31263.

34. Liang WX, Zou XX, Carballar-Lejarazú R, Wu LJ, Sun WH, Yuan XY, Wu SQ, Li $\mathrm{PF}$, Ding $\mathrm{H}$, Ni L, et al. Selection and evaluation of reference genes for qRTPCR analysis in Euscaphis konishii Hayata based on transcriptome data. Plant Methods. 2018;14:42.

35. Amorim LLB, Ferreira-Neto JRC, Bezerra-Neto JP, Pandolfi V, de Araujo FT, Matos MKD, Santos MG, Kido EA, Benko-Iseppon AM. Cowpea and abiotic stresses: identification of reference genes for transcriptional profiling by qPCR. Plant Methods. 2018;14:88.

36. Petriccione M, Mastrobuoni F, Zampella L, Scortichini M. Reference gene selection for normalization of qRT-PCR gene expression data from Actinidia deliciosa leaves infected with Pseudomonas syringae pv. Actinidiae. Sci Rep. 2015;5:16961.

37. Storch TT, Pegoraro C, Finatto T, Quecini V, Rombaldi CV, Girardi CL. Identification of a novel reference gene for apple transcriptional profiling under postharvest conditions. PLoS ONE. 2015;10:e0120599.

38. Gandia-Herrero F, Garcia-Carmona F. Biosynthesis of betalains: yellow and violet plant pigments. Trends Plant Sci. 2013;18:334-43.

39. De Loache WC, Russ ZN, Narcross L, Gonzales AM, Martin V, Dueber JE. An enzyme-coupled biosensor enables (S)-reticuline production in yeast from glucose. Nat Chem Biol. 2015;11:465.

40. Polturak G, Breitel D, Grossman N, Sarrion-Perdigones A, Weithorn E, Pliner M, Orzaez D, Granell A, Rogachev I, Aharoni A. Elucidation of the first committed step in betalain biosynthesis enables the heterologous engineering of betalain pigments in plants. New Phytol. 2016;210:269-83.

41. Sunnadeniya R, Bean A, Brown M, Akhavan N, Hatlestad G, Gonzalez A, Symonds W, Lloyd A. Tyrosine hydroxylation in betalain pigment biosynthesis is performed by cytochrome p450 enzymes in beets (Beta vulgaris). PLoS ONE. 2016;11:e149417.

42. Polturak G, Aharoni A. "la vie en rose": biosynthesis, sources, and applications of betalain pigments. Mol Plant. 2017;11:7-22.

\section{Publisher's Note}

Springer Nature remains neutral with regard to jurisdictional claims in published maps and institutional affiliations.
Ready to submit your research? Choose BMC and benefit from:

- fast, convenient online submission

- thorough peer review by experienced researchers in your field

- rapid publication on acceptance

- support for research data, including large and complex data types

- gold Open Access which fosters wider collaboration and increased citations

- maximum visibility for your research: over $100 \mathrm{M}$ website views per year

At BMC, research is always in progress.

Learn more biomedcentral.com/submissions 